\title{
Interações entre migrantes internacionais e brasileiros em situação de rua em São Paulo: reflexões sobre a narrativa de "disputa por vagas" nas políticas públicas locais
}

\author{
Interactions among homeless international \\ migrants and homeless brazilian citizens in São Paulo: \\ reflexions on the narrative of "vacancies competition" \\ on the local public policies
}

\author{
Janaína Dantas Germano Gomes \\ Universidade de São Paulo \\ Juliana Rocha MiRanda \\ Universidade de São Paulo
}

\begin{abstract}
Resumo Este trabalho sintetiza reflexões desenvolvidas a partir de experiências de atendimento e pesquisa sobre população em situação de rua na capital de São Paulo, numa extensão universitária da Faculdade de Direito da USP, a Clínica de Direitos Humanos Luiz Gama. No ínterim das atividades do grupo, oportunizou-se o contato com relatos e cenas de tensão entre brasileiros e migrantes internacionais, ambos classificados como parte da população de rua. $\mathrm{O}$ texto procura indagar acerca das interações entre os dois públicos, nos serviços locais, sobretudo em centros de acolhida especializados, a partir da narrativa de "disputa por vagas", expressão que decorre de fatores como o perfil socioeconômico diferenciado de migrantes internacionais e adução de brasileiros em situação de rua de que as políticas públicas favorecem "estrangeiros". No campo, construído por observação in loco, conversas informais e entrevistas, buscou-se conversar com trabalhadores e gestores de abrigos, que apresentaram, em sua narrativa, migrantes internacionais como "autônomos", em contraposição ao público brasileiro, descrito como "problemático" e "sem foco".
\end{abstract}


Pode-se perceber, desse modo, a polarização entre esses dois grupos, por meio de uma classificação que os hierarquiza e engendra um jogo discursivo que acaba por consolidar uns como mais aptos à garantia de direitos do que outros. Palavras-chave: PopulaÇÃo EM SituaÇÃo DE RUA. Migrantes InTERnACiOnaIs. Acolhimento. Serviços locais.

Abstract This paper gathers reflections developed from experiences of attendance and research about homeless people in the city of São Paulo, carried out by an university extension, the Legal Clinic in Human Rights "Luiz Gama" from Law School of the University of São Paulo. In its activities, the group had the oprtunity to receive reports and witnesses scenes of tension between brazilians and international migrants, both classified as part of the homeless population. The paper seeks to inquire about interactions between them in the local services, mainly in homeless shelters, based on the narrative of "vacancies competition", an expression that comes from factors such as differences in the socioeconomic profile of international migrants and the affirmation of some of the brazilian homeless people that local public policies put international migrants in advantage in comparison to them. The fieldwork was built by in loco observations, informal talks and interviews. We sought to talk to workers of homeless shelters, who presented international migrants as "autonomous" in opposition to the brazilians, who were presented as the "problematic" and "without focus". Then, it was possible to perceive tha polarization between the two groups, by means of a classification that hierarchizes them and creates a discursive game which ends up consolidating the idea that some deserve more protection to their rights than others.

Key-words: Homeless population. International migrants. Sheltering. LoCAL SERVICES.

\section{INTRODUÇÃO E CONSIDERAÇÕES TEÓRICO-METODOLÓGICAS}

O presente artigo é fruto das reflexões conjuntas no ínterim das atividades da Clínica de Direitos Humanos Luiz Gama (CDHLG). ${ }^{1}$ Escolhemos apresentar neste texto a temática da migração internacional

1 Mais informações sobre a Clínica de Direitos Humanos Luiz Gama em https://luizgama.wordpress.com/. 
na cidade de São Paulo a partir da atividade extensionista com pessoas em situação de rua. ${ }^{2}$

A CDHLG foi criada em 2009 na Faculdade de Direito da Universidade de São Paulo, por iniciativa de alunas e alunos, em busca de alternativas para o currículo da faculdade, que continha poucas matérias relacionadas à temática dos direitos humanos (GOMES, 2017). O grupo construiu-se, assim, com a proposta de oferecer formação crítica em direitos humanos, a partir de uma atuação reflexiva e estudo de um tema delimitado: a população em situação de rua, sobretudo a que se encontra no centro de São Paulo - não raro no próprio Largo de São Francisco, onde está localizada a faculdade.

Semanalmente, na CDHLG, são realizados encontros teóricos para discussão de textos, além das atividades práticas e, a cada semestre, novos alunos e alunas são selecionados para o projeto de extensão. As atividades práticas consistiram, ao longo dos anos de 2014 a 2017, em visitas a centros de acolhida e espaços de convivência para população em situação de rua, além de reuniões com outros atores e instituições envolvidos com o tema, como a Defensoria Pública, Comitê Pop Rua, a Pastoral do Povo de Rua e o Movimento Nacional da População de Rua, com vistas a compreender a condição de vida, as políticas de atendimento e os desafios jurídicos e sociais que se colocam a essa população.

A perspectiva desses contatos é sempre deslocar o papel do direito da fala para a escuta. Ainda, as atividades pautam-se em metodologias interdisciplinares, buscando a formação dos alunos e alunas e sua sensibilização aos métodos da antropologia, como a observação participante, a etnografia, o desenvolvimento de cadernos de campo e da sensibilização do olhar de alunas e alunos do direito para a imensa gama de questões para as quais a técnica jurídica não possui respostas prontas (GOMES, 2017).

\footnotetext{
2 As reflexões decorrentes deste trabalho foram aprimoradas e aprofundadas na forma de Trabalho de Conclusão de Curso pela autora. O trabalho foi aprovado, em 2017, e indicado pela banca para publicação. Ainda, em decorrência do início dos trabalhos na Clínica, também a aluna Fernanda Alves Rosa desenvolveu pesquisa de Iniciação Científica sobre o tema.
} 
Nas atividades em campo realizadas, as perguntas e conversas acontecem de maneira fluída, em geral, sobre as dificuldades individuais e do atendimento recebido nos equipamentos das políticas públicas locais. De maneira sistemática, o tema dos "estrangeiros" ou "haitianos" começou a surgir. Essas duas expressões de nossos interlocutores pareciam resumir aquilo que, como veremos, é um amplo e contínuo leque de nacionalidades e perfis que ingressam na cidade de São Paulo todos os anos.

Em que pese essas atividades práticas nunca terem se voltado especificamente para a população migrante internacional que de modo crescente se estabelece na cidade de São Paulo, observamos que, hoje, a reflexão sobre as condições de vida da população em situação de rua na cidade não pode ser dissociada desse contexto local. Pessoas vindas dos mais diferentes países têm chegado à metrópole e, com diferentes feições, cores e idiomas, na falta de alternativas, acabam por permanecer nas ruas, em centros de acolhida ou "ocupações" em prédios abandonados na região central da cidade.

Ecoando a ideia de que a pesquisa de campo não tem momento certo para iniciar (PEIRANO, 2014), começamos a indagar, a partir dos atendimentos, em geral a pessoas brasileiras nos espaços de assistência, sobre esses migrantes internacionais que se encontravam em situação de rua e a "rivalidade" que parecia se instalar.

Quando discorriam sobre esses "estrangeiros", "haitianos" ou "africanos", em geral, nossos interlocutores mencionavam especificamente o fato de que estariam "roubando as vagas de atendimento", e que as "políticas públicas davam melhor atendimento a essas pessoas", em detrimento deles próprios, brasileiros que há anos encontravam-se em situação de miséria nas ruas da cidade. ${ }^{3}$

Levando nossos interlocutores a sério, e buscando compreender qual o significado local do "roubo de vagas", passamos a tentar com-

Em campo, pessoas negras de pele escura oriundas de outros países foram com frequência generalizadas como "haitianos" - sobretudo em 2014 e início de 2015 - e como "africanos", nas interlocuções posteriores. 
preender a aparição dessa categoria acusatória na narrativa de nossos interlocutores, e entender qual o potencial analítico e problematizador desta no tema da migração internacional na cidade de São Paulo.

Para tanto, utilizaremos de fragmentos de nossas visitas a campo, realizadas a seis centros de acolhida para pessoas em situação de rua, no ano de 2017, para tentar apresentar a narrativa encontrada em campo da "disputa por vagas", relacioná-la com a questão da população em situação de rua na cidade de São Paulo, com as políticas públicas para migrantes para, finalmente, pensar como as "pessoas em situação de rua" e as "pessoas migrantes" mesmo que em ambos os casos estejam sem moradia, são tratadas como categorias de pessoas distintas, sendo estas mais valoradas que aquelas, sob a ótica das pessoas nacionais em situação de rua.

Buscaremos confrontar, também dados oficiais obtidos pelo sistema de Acesso à Informação da Prefeitura de São Paulo. Essa abordagem justifica-se pelo potencial de comparar dados do cotidiano, obtidos pela pesquisa de campo, com os dados oficiais, fornecidos pelo poder público. Trata-se de um exercício que possibilita a construção de conclusões muitas vezes não previstas formalmente (BECKER, 2014). Desse modo, torna-se possível diagnosticar problemas e obstáculos ou ressaltar acertos e pontos positivos (ALMEIDA, 2014).

\section{A aproximação com a temática nas ruas de São Paulo}

Em 2014, em uma dessas atividades de escuta, no Chá do Padre, serviço mantido pelo Serviço Franciscano de Solidariedade (SEFRAS), a equipe da CDHLG teve seu primeiro contato com um grupo de estrangeiros. No serviço, que hoje oferece outro tipo de atendimento, diariamente eram servidos pão e chá para pessoas em situação de rua, além de promovidas atividades de convivência. Ali, conversamos com homens e mulheres de diversas idades e, alguns deles, ambulantes, vendedores, prostitutas que, na busca por um local de descanso e um alimento, entravam no Chá do Padre. O espaço, fisicamente, conformava-se como um grande salão com cerca de 400 cadeiras enfileiradas e voltadas para 
um palco. As portas abertas permitiam a entrada de quem se interessasse pelo espaço.

Certa vez, três homens, negros, altos - certamente com mais de 1,80 - e magros vindos do Quênia - ingressaram no local. Estavam trajando roupa social e tentando se comunicar com a funcionária do equipamento em inglês. $\mathrm{O}$ estranhamento foi imediato, as alteridades ali eram muito marcantes: o corpo, o idioma, o traje. Da parte dos conviventes do Chá do Padre, formou-se uma tensão, que foi mediada pela funcionária do serviço, evitando algum tipo de confronto ou agressão física que parecia borbulhar. Quando o grupo da CDH Luiz Gama passou a conversar com o trio queniano em inglês, a pedido da funcionária, alguns conviventes nos abordaram e fizeram alegações de que "eles pegam nossas vagas", "eles vão passar ebola".

Os quenianos, por sua vez, perguntaram quem eram aquelas pessoas, por que estavam ali, o que era aquele lugar. Mostraram-se chocados com a descoberta de que, no Brasil, lugar ao qual vieram para conquistar o sonho de serem atletas, havia pessoas que moravam nas ruas. "Mas essas pessoas não têm família?"; "Elas não podem andar até suas casas?" Com alguma surpresa e dificuldade, a equipe explicou que aquelas pessoas, em sua maioria, possuíam vínculos rompidos com suas famílias, ou algum tipo de problema de saúde - buscando evitar explicações a partir de estereótipos como o uso de drogas, por exemplo - que poderia ter levado ao isolamento nas ruas.

$\mathrm{O}$ encontro entre essas realidades - três homens vindos do Quênia para viver um sonho, alunas e alunos de uma Faculdade de Direito altamente elitizada e brasileiros em situação de rua rendeu muitas reflexões. Como seria possível explicar que pessoas vindas da África, continente que pouco conhecemos e cujos países e culturas são dificilmente distinguidos por nós, mas muitas vezes identificados como mais pobres e subdesenvolvidos, não compreendiam o que eram pessoas pobres em situação de rua? A naturalização da miséria em nossa cidade, na qual mais de 15 mil pessoas se encontram nas ruas (FIPE, 2015), colocou-se à prova quando tivemos que explicar, a pessoas de outros países, como era possível tantas pessoas juntas em situação de rua e de pobreza extrema. 
A comoção e os olhares dos usuários brasileiros para os quenianos e o nosso grupo, enquanto tratava com eles era visível, e expressava uma forte insatisfação. Chamados de "haitianos" e o temor do "ebola" eram noções confusas acerca da nacionalidade e possíveis perigos da alteridade daqueles indivíduos. Por que os "haitianos", per si, seriam um problema para aquelas pessoas?

Em outra oportunidade, um homem muito negro do Rio de Janeiro começou seu atendimento conosco afirmando "sou muito preto, mas não sou haitiano não, hein. Sou daqui do Brasil, sou do Rio de Janeiro". Assim como no encontro com o grupo queniano, ficou claro que a cor negra desse homem acabara por envolvê-lo em conflitos nas ruas por ser ele "haitiano", e era necessário frisar a todo momento que ele era "daqui".

A vivência no Grupo de Trabalho Migrações e Refúgio da Defensoria Pública da União (DPU) de integrantes de grupo ${ }^{4}$ permitiu o acesso a novas informações sobre essas tensões em campo. Chamava a atenção algumas reações dos outros usuários da DPU que chegaram a enunciar que "eles estão aqui para roubar nossos benefícios, nossas aposentadorias" e que eles vinham para o Brasil "cheios de doenças da África".

Da parte de atendentes, servidores e estagiários da DPU, era possível inferir certa resistência em atender a esse público. A justificativa primeira era o idioma ou porque esse tipo de atendimento costumava demorar muito em comparação com os tradicionais de cível, previdenciário, criminal e tributário.

O contato com pessoas migrantes internacionais em situações semelhantes às pessoas em situação de rua, e sendo atendidas nos mesmos espaços e serviços - como o Chá do Padre e, como mencionavam nossos interlocutores, "roubando vagas" nos centros de acolhida, encaminhou a nossa reflexão não aos motivos que levam as pessoas à migrarem, ou ao tamanho ou à constância do fluxo, suas nacionalidades, nem tampouco investigar o cunho xenofóbico ou racista que efetivamente essa narrativa possui.

$4 \quad$ Entre elas a autora deste texto Juliana Rocha. 
Nos termos de DIEME (2016) "falar de imigração é tratar também explícita ou implicitamente de política de acolhimento institucional". A política de acolhimento analisada pelo autor, ainda que voltada especificamente aos haitianos, fala um pouco de alguns dos desafios colocados neste contexto: um acolhimento realizado por muitas organizações diferentes, recente quanto ao público de haitianos e de países do continente africano e suas particularidades culturais, idiomáticas e de motivos para as suas imigrações.

O que nos parece de interesse problematizar é a política de acolhimento que, juntando pessoas de perfis diferentes e com necessidades distintas em um mesmo serviço de atendimento, aquele voltado para pessoas em situação de rua, conhecido por sua precariedade, promove, em nossa hipótese de trabalho, essa lógica de disputas. Assim, procuramos se e em quais moldes a medida não seria propícia ao diálogo ou à troca entre esses indivíduos, mas potencializaria o sentimento de invisibilidade da população em situação de rua ante a hipervisibilidade e abertura de novos serviços para pessoas migrantes internacionais.

\section{O CONTEXTO DA IMIGRAÇÃO: SITUAÇÃO DE RUA}

Dada a realidade de encontro entre nacionais e migrantes internacionais no circuito da rede de acolhimento, faz-se importante localizar a discussão, ao contextualizar a população em situação de rua e a atual configuração da imigração para São Paulo. Do ponto de vista histórico, no Brasil, o fato de haver pessoas nas ruas era tratado sob a ótica individual do fracasso, insuficiência e mendicância - o que manteve a questão longamente atrelada à religiosidade e instituições de caridade.

Foi somente a partir da década de 1980 que o tema passou a ter contornos mais concretos e a ser problematizado socialmente (FRANGELLA, 2004). Em plano federal, a articulação da sociedade civil, em especial do Movimento Nacional da População em Situação de Rua (MNPR), conquistou, em 2009, a instituição de uma política nacional (FERRO, 2012). Nos termos do Decreto Federal nº. 7.053/2009: 
Considera-se população em situação de rua o grupo populacional heterogêneo que possui em comum a pobreza extrema, os vínculos familiares interrompidos ou fragilizados e a inexistência de moradia convencional regular, e que utiliza os logradouros públicos e as áreas degradadas como espaço de moradia e de sustento, de forma temporária ou permanente, bem como as unidades de acolhimento para pernoite temporário ou como moradia provisória.

A cidade de São Paulo é referência nacional sobre o assunto. Trata-se da cidade brasileira com maior número de pessoas em situação de rua: 15.915 (FIPE, 2015), fator que permitiu a criação de ampla rede de atendimento e assistência a esse público (DE LUCCA, 2007). Ainda em 1997, foi editada a Lei de Atenção à População de Rua, ${ }^{5}$ regulamentada em 2001. ${ }^{6}$ A lei implicou o fortalecimento e a consolidação dessa rede, ao sedimentar os princípios que devem orientar os procedimentos e, entre outras coisas, elencar os serviços e tipos de atendimento prestados. Entre eles, o albergue destaca-se como principal política para a população em situação de rua (DE LUCCA, 2010).

O tema do acolhimento a pessoas sem moradia, ainda que transitoriamente, ganha novos contornos no contexto de grande demanda por acolhimento de migrantes internacionais no município de São Paulo que chegam na cidade sem quem possa recebê-los. Esse dado está, fundamentalmente, inserido num processo de globalização das migrações, o qual tende a intensificar-se, devido à permanência ou aprofundamento dos fatores de mobilidade (WIHTOL DE WENDEN, 2016).

Num contexto em que as migrações já não se restringem ao movimento sul-norte, mas ocorrem fortemente no eixo sul-sul, o Brasil figura como polo de atração. Constata-se, a partir de 2010, o aumento expressivo dos fluxos para o país e, no biênio 2013-2014, foi registrado o maior ingresso e contingente de imigrantes desde a década de 1930, a

Lei Municipal $\mathrm{n}^{\circ} .12 .316$ de 1997.

6 Decreto Municipal no 40.232 de 2 de janeiro de 2001. 
época das grandes imigrações de italianos, alemães e japoneses, principalmente (UEBEL \& RUCKERT, 2017).

O Brasil consolidou-se como receptor de todos os principais grupos migratórios, antes exclusivos aos países do hemisfério norte. Quantificando $1 \%$ do total da população brasileira, os grupos de imigrantes tradicionais continuaram em alta: $38 \%$ dos imigrantes do biênio eram de origem portuguesa, italiana e espanhola, $8 \%$ do Japão e 7\% da Bolívia. Mas destacou-se o crescimento considerável dos novos fluxos, entre eles, de haitianos, libaneses, colombianos, cubanos, filipinos, indianos, angolanos, nigerianos, senegaleses, sírios e outras nacionalidades não tradicionais (UEBEL \& RUCKERT, 2017).

São Paulo é a cidade brasileira que mais recebe migrantes internacionais e se deparou, diante do aumento dos fluxos para a cidade, com uma demanda muito grande por acolhimento na rede municipal. Não havia, contudo, estrutura específica para atender a esse contingente. Assim, os espaços para a população de rua passaram a ser procurados. Segundo a Secretaria Municipal de Desenvolvimento e Assistência Social "em 2013 e 2014, a maior parte dos imigrantes estava nos complexos de serviços à população em situação de rua como Canindé, Prates e, principalmente, Arsenal da Esperança". ${ }^{7}$

Diante da insuficiência de vagas, em moldes incrementalistas, que respondiam à urgência da demanda, foram sendo criados espaços especializados para imigrantes em situação de rua. No segundo semestre de 2014, foi inaugurado o Centro de Referência e Atendimento para Migrantes (CRAI) e o Centro de Acolhida para Imigrantes Bela Vista; em 2015, o Centro de Acolhida para Imigrantes Pari e o Centro de Acolhida Especial para Mulheres Imigrantes Penha; e em 2016, o Centro de Acolhida Especial para Mulheres Imigrantes Belém. ${ }^{8}$

Além disso, diante da crescente demanda por vagas e da pressão midiática, criou-se uma janela de oportunidade para a criação de uma

7 Solicitação feita à Secretaria municipal de Assistência e Desenvolvimento Social, protocolo $n^{\circ}$. 23.624, aberto em 18/07/2017 e atendido em 07/08/2017.

8 Solicitação feita à Secretaria Municipal de Assistência e Desenvolvimento Social, protocolo $\mathrm{n}^{\mathrm{o}}$. 23.624, aberto em 18/07/2017 e atendido em 07/08/2017. 
política local. Assim, foi tomada uma série de medidas no âmbito da Coordenação de Políticas para Migrantes da Secretaria Municipal de Direitos Humanos e Cidadania (SMDHC) e da Câmara Municipal, até que se chegou à sanção da Política Municipal para a População Imigrante. ${ }^{9}$

A referida norma estabelece os direitos humanos, a igualdade, o combate à xenofobia e o racismo e a promoção dos direitos sociais como princípios da política municipal. Além disso, cria o Conselho Municipal de Imigrantes. O dispositivo tem por objetivo maior tornar políticas de Estado as iniciativas de promoção e defesa de direitos de imigrantes, assim como as de acolhimento. As últimas são especialmente relevantes quando considerados os dados mais recentes sobre população em situação de rua na cidade, que abordo no tópico a seguir.

Importante ressaltar que tanto a população de rua como a população imigrante tem aumentado na cidade de São Paulo, o que torna imprescindível olhar para a realidade das políticas públicas voltadas para ambas, especialmente no que diz respeito às dificuldades que podem surgir no atendimento da rede de acolhimento a essas pessoas.

\section{RESPOSTA OFICIAL: PANORAMA INSTITUCIONAL DO ACOLHI- MENTO A MIGRANTES INTERNACIONAIS}

Considera-se que a política de acolhimento à população imigrante em situação de rua é institucionalizada, tendo em vista que se encontra formalizada na regra jurídica. Ou seja, o seu funcionamento, assim como os deveres e obrigações dos agentes envolvidos encontram-se previstos nas normas que definem a finalidade buscada (BUCCI, 2016). A base normativa, isto é, as disposições que instituem o programa e especificam seu funcionamento, é municipal.

Na Lei de Atenção à População de Rua, é prevista, no artigo $4^{\circ}$., a implantação e a manutenção de alguns serviços, entre os quais os albergues (Inciso II), que devem ser providos de recursos humanos e materiais para a acolhida e alojamento. São elencadas como alvo desse

9 Lei Municipal no .16 .478 de 21 de junho de 2016. 
serviço pessoas em tratamento de saúde, imigrantes recém-chegados, situações de despejo, desabrigo emergencial e mulheres vítimas de violência. Ainda, fica estabelecido que deve haver funcionamento permanente, com condições para higiene pessoal, alimentação, guarda de volumes e serviços de documentação e referência na cidade.

De acordo com a regulamentação da referida lei, a coordenação do Programa de Atenção à População em Situação de Rua fica a cargo da Secretaria Municipal de Assistência e Desenvolvimento Social (SMADS), conforme previsto no artigo $1^{\circ}$. Objetiva-se, assim, a construção de uma ampla rede de serviços e programas de caráter público que garantam, entre outras coisas, acolhida digna em instalações salubres, seguras e com grau de privacidade compatível com processo de reinserção social (art. $2^{\circ}$.).

A operacionalização do serviço, por sua vez, pode ser realizada pela Prefeitura diretamente, ou por contratos e convênios de prestação de serviços com associações civis de assistência social devidamente registradas no Conselho Municipal da Assistência Social (art. $3^{\circ}$.).

Na Política Municipal para a População Imigrante, cuja implementação deve ser transversal e articulada pela Secretaria Municipal de Direitos Humanos e Cidadania ( $\operatorname{art.} 1^{\circ}$.), algumas disposições reforçam o acolhimento aos imigrantes. $\mathrm{O}$ artigo $7^{\circ}$., inciso I, estabelece como uma das ações prioritárias a garantia da população imigrante ao direito à assistência social "assegurando o acesso aos mínimos sociais e ofertando serviços de acolhida ao imigrante em situação de vulnerabilidade social" (grifos das autoras). Além disso, na regulamentação, ${ }^{10}$ tem-se a previsão de que a SMADS oferte serviços específicos para essa população, assegure atenção ao princípio da reunião familiar e garanta que as casas de acolhida atuem na construção da autonomia dos usuários e em sua inclusão social, em articulação com outras políticas.

Em se tratando da estrutura, de acordo com informação oficial, existem quatro centros de acolhida: o Centro de Acolhida para Imigrantes Bela Vista, que acolhe 190 homens; o Centro de Acolhida Especial

10 Decreto Municipal no .57 .533 , de 15 de dezembro de 2016. 
para Imigrantes Belém, que acolhe 300 pessoas, sendo mulheres com ou sem filhos e, preferencialmente, imigrantes angolanas; o Centro de Acolhida para Imigrantes Pari, com capacidade para acolher 190 homens e o Centro de Acolhida para Mulheres Imigrantes Penha, que tem capacidade para 80 mulheres. $^{11}$

Em 2015, havia cerca de 74 migrantes internacionais dormindo nas ruas e outros 556 nos Centros de Acolhida (FIPE, 2015). De acordo com o Produto V - Relatório Completo do Censo da População em Situação de Rua de São Paulo, essa quantidade revela aumento significativo em relação à contagem anterior, realizada em 2011. Nesta, foram contabilizados 29 migrantes internacionais nas ruas, e 85 nos Centros de Acolhida.

O relatório traz, ainda, outras observações sobre o perfil dos migrantes acolhidos. Por exemplo, a média de idade deles (35,5 anos) é menor do que a dos acolhidos em geral (42,6 anos). Em relação à raça, acima da média dos acolhidos, que é $70 \%$, a proporção de não brancos é $78,1 \%$. Entre eles, $61 \%$ consideram-se negros, o que o Relatório atribui à provável origem africana. Destaca-se, ainda, segundo o censo, a presença de migrantes internacionais em 55 dos serviços da rede de acolhida, sendo que o grupo representa a menor proporção dos acolhidos que já precisaram pernoitar na rua. Ainda, entre as mulheres acolhidas com filhos, 13\% não são brasileiras (FIPE, 2015).

Importante ressaltar que os dados do censo, além de estarem desatualizados, têm algumas particularidades que inviabilizam a dimensão de quantos imigrantes estão acolhidos em 2017. Por exemplo, não foram contabilizadas as pessoas - brasileiras e imigrantes - que moram em ocupações, por não serem consideradas população em situação de rua. Além disso, à época da contagem, havia somente um centro de acolhida - o Centro de Acolhida para Imigrantes Bela Vista, com capacidade para 190 homens (FIPE, 2015). Tal dado é relevante uma vez que, ante as tensões com pessoas em situação de rua brasileiras, as ocupações, em especial aquelas que conseguem congregar uma maioria

11 Solicitação feita à Secretaria municipal de Assistência e Desenvolvimento Social, protocolo ${ }^{\text {o }}$. 23.624, aberto em 18/07/2017 e atendido em 07/08/2017. 
de uma mesma nacionalidade, mostram-se como alternativas viáveis e facilitadoras da instalação dessas pessoas no país.

Ainda, não foram contabilizados os migrantes acolhidos na Casa do Migrante - um abrigo mantido pela Missão Paz, da igreja Nossa Senhora da Paz, localizada no bairro do Glicério e com capacidade para 110 pessoas - porque ele não pertence ou é conveniado com a Prefeitura (FIPE, 2015). Sabe-se que hoje existe no Pari outra casa não vinculada ao Estado, que acolhe, sobretudo, refugiados sírios, o chamado Centro de Acolhida da Mesquita.

Em busca de maior precisão, foi realizado um pedido de acesso à informação, pelo portal E-sic da prefeitura, com base na Lei de Acesso à Informação. ${ }^{12}$ Em síntese, solicitou-se esclarecimentos sobre quantas são as vagas usadas no momento por homens, mulheres e crianças, além da quantidade de brasileiras no Centro de Acolhida Especial para Imigrantes Belém, que acolhe 300 mulheres com ou sem filhos e, preferencialmente, angolanas. A SMADS respondeu que a taxa de ocupação dos quatro serviços especializados, assim como dos equipamentos em geral é rotativa e varia muito conforme o dia. Estimou, assim, que para os serviços voltados a migrantes internacionais tem-se "entre $90 \%$ e $95 \%$ de ocupação diariamente". ${ }^{13}$

Em outro pedido de acesso à informação, dessa vez destinado à Secretaria Municipal de Habitação (SEHAB), indagou-se sobre regras e/ou filas específicas para a concessão de benefícios em programas de habitação a migrantes internacionais e se existem dados oficiais a respeito do número deles em ocupações irregulares. ${ }^{14}$ A Secretaria respondeu que o atendimento ocorre por meio do auxílio aluguel, fundado na Portaria $n^{\circ}$. 131/2015, e que também atende a pessoas em situação de

12 Lei Municipal no 12.527 de 18 de novembro de 2011.

13 Prezada munícipe, A Secretaria Municipal de Assistência e Desenvolvimento Social informa que a taxa de ocupação desses quatro serviços, bem como, dos demais equipamentos, é rotativa e varia muito conforme o dia. Para os serviços que acolhem imigrantes temos, em média, entre $90 \%$ e $95 \%$ de ocupação diariamente. Atenciosamente, José Antonio de Almeida Castro Chefe de Gabinete.

14 Solicitação feita à Secretaria municipal de Habitação, protocolo n ${ }^{\circ}$. 23.626, aberto em 18/07/2017 e atendido em 07/08/2017. 
rua. Imigrantes podem ser contemplados, mas não pelo critério da migração e sim pelo de vulnerabilidade social, caso apresentem.

Quanto à questão das ocupações, a SEHAB informou que, em consulta à Divisão Técnica Regional Centro - DEAR Centro, não há um mapeamento nas ocupações que indique a quantidade de imigrantes. De acordo com a divisão, na ocupação do edifício Marrocos, já reintegrada, havia grande número de imigrantes. ${ }^{15}$

\section{Dificuldades no atendimento}

A enorme demanda por acolhimento a migrantes internacionais é uma novidade para a rede de atendimento. Em campo, foram levantadas algumas situações que se mostraram desafiadoras para a prestação do serviço. Essas podem surgir nas dinâmicas entre os atendidos e a equipe, entre migrantes de diferentes origens e entre migrantes e brasileiros/ as. As barreiras de idioma, em geral, foram pouco mencionadas, mas se destacou, genericamente, a maior dificuldade em atender a pessoas que não são lusófonas ou latinas.

Em visitas a centros de acolhida femininos, especificamente, duas interlocutoras, funcionárias dos serviços, chamavam de "questões culturais" ou "diferenças culturais" algumas complicações. Por exemplo, no que diz respeito à alimentação, foram apontadas reclamações em relação ao arroz com feijão - refeição tipicamente brasileira e, por ser de baixo custo, com frequência servida nos centros de acolhida. Em um deles, o problema é mitigado pelo preparo habitual do "tutu", comida mais bem recebida pelas usuárias.

15 Sobre a ocupação, algumas informações disponíveis em: <http://g1.globo.com/sao -paulo/noticia/2016/10/familias-que-ocupavam-antigo-cine-marrocos-deixam-o-edificio.html $>$. Consta na notícia que foram removidas com uso de força policial cerca de 127 famílias, e que 45\% das pessoas ocupantes ali eram migrantes internacionais. Contudo, a ocupação também foi chamada de "torre de babel" por seu número de mais de 600 famílias sendo mais de $60 \%$ migrantes internacionais em outras notícias, como: <http://sao-paulo.estadao.com.br/blogs/diego-zanchetta/justica-da-6-meses-para-475-familias-deixarem-cine-marrocos/ $>$. 
Em outro centro, apesar de conseguirem fazer com frequência o "fufu", alimento à base de fubá, a assistente social da equipe alerta para a importância dos acolhidos se esforçarem para se adaptar. Ela enfatiza a importância de não impor a cultura brasileira e se manter aberta às culturas dos acolhidos, mas alerta que é preciso ser pontual e lidar com a realidade que se tem: um centro de acolhida, no Brasil, onde "não é possível agradar a todos".

A questão da qualificação para o trabalho foi levantada por uma das interlocutoras no caso das mulheres acolhidas. Segundo acredita, as que vieram do continente africano costumam não ter experiência ou preparo profissional, pois "costumavam ser mantidas por seus maridos".

Outras situações foram narradas, ademais, como a forma como mães de alguns países lidam com o cuidado com os filhos - jeito de pegar, forma de repreender - e com higiene, ao descartarem fraldas em locais de convivência. Também foram mencionados estranhamento e dificuldade em tentativas de desenvolver trabalho de educação sexual com mulheres acolhidas.

Houve, ainda, em um dos equipamentos, o caso dos muçulmanos, que precisavam higienizar/ungir os pés e as mãos antes das orações. Esse preparo acabava deixando o chão do banheiro encharcado na área das pias e incomodava os conviventes que não partilhavam do costume. A solução que a gestão do serviço encontrou foi adaptar umas torneiras baixas, deixando o espaço para a higienização de pés e mãos.

Outro caso foi o do equipamento no qual as próprias usuárias eram responsáveis pela limpeza. Segundo a equipe, as brasileiras coagiam migrantes a limparem sozinhas e faziam ameaças para que estas não reclamassem para as funcionárias. A justificativa usada era de que as migrantes estavam "no lugar das brasileiras" e, portanto, precisavam ajudar mais que estas.

Percebe-se, portanto, que diversidade, nos centros de acolhida, pode ser entre brasileiras e migrantes, migrantes de países diferentes ou mesmo migrantes de um mesmo país com diferentes pertencimentos culturais. As dificuldades de convivência estão tanto nas relações entre usuários, como entre estes e a equipe. Foi destacado como ponto 
positivo para promover contato e integração, em alguns dos espaços, a presença de alguns trabalhadores que também são migrantes.

\section{Migrantes internacionais aCOlHidos Versus POPUlaÇão EM SITUAÇÃO DE RUA}

Embora a legislação trate o segmento de migrantes internacionais acolhidos como parte da população em situação de rua, foi constatada, na fala local, uma forte divisão entre os dois públicos. A partir da construção de estereótipos, cria-se uma classificação que hierarquiza as pessoas acolhidas: migrantes são identificados como autônomos e independentes, enquanto brasileiros em situação de rua são associados a drogas, criminalidade e falta de foco.

Assim como os espaços de acolhimento da população em situação de rua em geral, os equipamentos especializados para migrantes oferecem quarto e alimentação, além de atendimento social, como encaminhamento para trabalhos, para tirar documentos, para serviços de saúde etc. Os objetivos são também promover inserção na sociedade e ajudar na construção do processo de autonomia dos migrantes.

A diferença, em campo, reside no perfil dos dois públicos. O acolhimento a migrantes é visto como algo transitório, para recém-chegados, a ser superado em pouco tempo, com a adaptação no país e a conquista das condições para trabalhar. Isso ocorre, porque imigrantes são pessoas que "vieram ao país com objetivos a alcançar depois de terem deixado seus países", são "autônomos" e "não têm medo de trabalhar". Por causa disso, a rotatividade nos centros de acolhida especializados costuma ser muito grande.

Segundo uma das interlocutoras, o trabalho nesse tipo de equipamento é gratificante, pois "não se trata de um grupo repetitivo, que tem sempre os mesmos problemas". Os imigrantes "não vieram para estacionar em centro de acolhida", são excepcionais os casos dos que ultrapassam um ano, ficam mudando de um abrigo para outro ou não se empenham em conseguir trabalho. Quando isso acontece, os motivos são 
dificuldades por causa da idade, problema de saúde, problema emocional, dependência química etc. Indivíduos imigrantes com histórias desse tipo foram descritos como "fora do perfil da casa" ou como portadores de comportamento que não corresponde à "realidade do atendimento".

Brasileiros em situação de rua são, no entanto, o oposto dos migrantes segundo os interlocutores. Tendem a "depender muito mais tempo da rede de assistência e a demandar intervenções muito mais complexas", dadas as razões que acarretaram o acolhimento. Apresentam, com frequência, histórico de rompimento de vínculos familiares, problemas com álcool e drogas, quadro de problemas de saúde mental. O trabalho com eles é "mais difícil", o que inspira a afirmação de uma das interlocutoras que atende somente a migrantes internacionais, de que "admira muito as colegas, assistentes sociais, que trabalham com população em situação de rua".

\section{ConsideraÇões FINAIS: DIREITOS EM CENÁRIO DE ESCASSEZ}

O cenário de escassez das políticas públicas para pessoas em situação de rua, suas dificuldades e desafios, seja pela heterogeneidade das pessoas atendidas, seja pela especificidade dos atendimentos à saúde, uso de drogas, entre outros, vem sendo apontado (RUI, 2010 DE LUCCA, 2007). A tentativa de atendimentos segmentados de acordo com "perfis" de usuários é constante, criando-se a todo momento novas políticas públicas, com foco em diferentes públicos - a exemplo das "alas LGBT" em centros de acolhida, centros de referência específicos para estes e outros públicos.

O surgimento de um novo grupo populacional que ingressa nas fileiras pelas vagas e atendimentos acarreta, como vimos, alguns tensionamentos e estranhamentos, seja entre os próprios usuários, seja para com os profissionais que realizam os atendimentos.

Fonseca e Cardarello em texto denominado "Direitos dos Mais e Menos Humanos" (1999) afirmam que a noção de direitos humanos é traduzida na prática, e "depende de relações de poder em contextos históricos específicos, sempre expressos em categorias semânticas pre- 
cisas". Para apresentar suas reflexões, afirmam que certas categorias são eleitas como "alvo merecedor de campanhas em defesa de direitos humanos". Para tanto, constroem sua argumentação a partir de exemplos em que pessoas são valoradas de modo diferente a partir de ideais construídos ativamente em torno de algumas categorias, como a proteção dos direitos indígenas ou da infância.

Por exemplo, em 1997, quando três jovens abastados de Brasília colocaram fogo em um índio pataxó, justificaram-se dizendo que pensavam tratar-se "apenas de um mendigo". Segundo as autoras:

Ao apresentar tudo como um mal-entendido - como se fosse permissível, ou em todo caso menos condenável, atear fogo num mero mendigo - os rapazes trazem à tona um sistema de classificação que separa os humanos dos não-humanos (p. 4).

Os autores passam, então, a refletir sobre os processos de exclusão que o jogo discursivo dos direitos humanos muitas vezes coloca em movimento, não apenas "reificando" categorias, mas também promovendo de maneira velada a segmentação, a hierarquização de outras. Em suma, os discursos emplacados pelos direitos humanos nem sempre "surtem os efeitos desejados" (p. 5), podendo significar a exclusão e o prejuízo de outros grupos sociais.

Essa argumentação nos parece preciosa para o contexto que descrevemos. Estamos diante de pessoas que, em situação de rua, estão diante de novos investimentos e recursos focados em pessoas migrantes internacionais, com as quais elas passariam, sob sua lógica, a "competir por vagas". Parece-nos que, na lógica das pessoas em situação de rua, as pessoas migrantes internacionais recém-chegadas seriam mais vistas e mais protegidas do que elas, há tantos anos em situação de vulnerabilidade.

A necessidade de atendimento conjunto de pessoas tão diferentes denuncia não apenas o despreparo da política de acolhimento para migrantes em São Paulo, mas também, a precariedade do acolhimento 
para pessoas em situação de rua na cidade, em que a constatação do déficit de vagas e lacunas do atendimento é uma realidade.

A necessidade de um atendimento específico para a população migrante, que se coloca por diversos motivos, não pode recair, contudo, nesses jogos discursivos que acabam por consolidar uns como mais aptos a recebê-los do que outros, ou, nas palavras das autoras supracitadas, como "mais e menos humanos". Estamos diante de um amplo espectro de pessoas que necessitam de atendimento e cujas precariedades atingem, fazem sofrer, dormir nas ruas, e vivenciar todo o tipo de violação a direitos.

Como poderemos, enquanto gestores, juristas, pesquisadores, atuar fora dessas caixas compartimentalizadas em que se colocam migrantes de um lado, pessoas em situação de rua de outro, e atuar diante de um quadro de garantia ampla a direitos e compreensão de que as violações e as particularidades estão também em um movimento dinâmico e de intersecções?

No quadro de debates sobre direitos diferenciados e políticas de reconhecimento, ganha destaque a ideia de intersecção entre raça, nação, sexualidade e gênero (MOUTINHO, 2014). Nesse sentido:

\footnotetext{
Como nos tornamos "nós"? Como nos tornamos "eles"? Como alguns se tornam "nós" e outros "eles"? $\mathrm{Ou}$, talvez a melhor maneira de formular essa pergunta seja: de que modo os dispositivos de poder produzem a diferença entre o "nós" e "eles"? Muitas das recentes reflexões acerca da produção da diferença e da análise da desigualdade social vêm investindo na articulação dos chamados "marcadores sociais da diferença". As questões acima colocadas informam ora explícita, ora implicitamente esse campo de análise.
}

Marcadores sociais da diferença são sistemas de classificação usados para organizar a experiência por meio da identificação de indivíduos com determinadas categorias sociais relacionadas à raça, sexualidade, origem. 
Para Zamboni (2014), cada uma das categorias de classificação está associada a uma posição social, possui uma história e atribui certas particularidades em comum aos indivíduos nela agrupados. Os marcadores sociais de diferença não são uma lista definitiva, tampouco universal para diferentes contextos sociais. Sua perspectiva analítica compreende que diferenças e desigualdades não são dados da natureza, mas socialmente construídas e precisam ser contextualizadas em termos de tempo e espaço.

Algumas das particularidades, compartilhadas com certos indivíduos e não com outros, assumem peso profundo na definição da experiência dos indivíduos, o que as conecta com relações e sistemas de poder mais amplos e que atuam na produção e reprodução de desigualdades (ZAMBONI, 2014). No cotidiano da atuação com pessoas em situação de rua, por exemplo, migrantes e nacionais é uma das classificações possíveis, havendo tantas outras que poderiam ser mencionadas ("noias" e "limpos", vagabundos e trabalhadores, pai de família, mãe, "da vida").

O que nos importa salientar nesta oportunidade é que em esse cenário de pobreza, déficit de vagas, falta de recursos e dificuldades no atendimento ampliado, a segmentação de grupos, visibilidades, pode colocar-se nociva a todos os que necessitam de atendimento, como evidenciado pelas narrativas de "disputa de vagas" e tensões vivenciadas nos espaços de atendimento.

Naturalmente, diferenças culturais, racismo, xenofobia compõem o quadro geral desses tensionamentos. O que desejamos destacar, em particular, são as segmentações que tomam corpo por meio do estado, das políticas de atendimento, e da dificuldade de ampliar e destacar os cuidados com as pessoas em situação de rua - migrantes ou não - que, continuam como "meros mendigos", no imaginário social.

Outra manifestação nociva da segmentação está no adoecimento psíquico de funcionários que, para usuários migrantes ou nacionais, devem decidir cotidianamente como empregar os parcos recursos à disposição, e lidam com complexas trajetórias de vida que não têm fácil resolução (SANTANA; ROSA, 2016). Entre as razões que ouvimos, a necessidade de escolher "quem vai dormir na rua hoje", pela falta de 
serviços, é fonte de angústia e desânimo perante o serviço prestado e os usuários atendidos.

A busca pelo atendimento e garantia de direitos a essas populações, tal qual vem sendo feita, na perspectiva deste trabalho, precisa ser problematizada. Antes de lançar luz nas diferenças entre esses grupos sociais, propomos pensar nas intersecções, nos aspectos em comum que tocam a todos eles.

A violação de direitos, a escassez de recursos, a miséria com quem vem sendo acolhido pelas políticas locais, as violações a direitos de moradia, saúde, dignidade colocam-se a todos e todas. Como poderíamos, a partir do discurso jurídico, e do discurso dos direitos humanos, reivindicar um cuidado e a construção de sujeitos de direito que não acarretassem em novas e prejudiciais segmentações? Como seria possível construir, em nosso imaginário social, na garantia de direitos, um valor pela vida e pela dignidade humanas que tornasse impossível que alguém fosse um "mero mendigo" ou que tivesse que dormir - independente de raça, cor, orientação sexual ou nacionalidade - mais uma noite, nas ruas de nossas cidades?

\section{REFERÊNCIAS}

ALMEIDA, Vera Ribeiro. What is the contribution of the dialogue with social sciences for Brazilian legal research? An analysis from an empirical study in the small claims criminal court in the city of Rio de Janeiro. Brazilian Journal of Empirical Legal Studies, v. 1, p. 40-58, 2014.

BECKER, Howard S. A Epistemologia da Pesquisa Qualitativa. In: Revista de Estudos Empíricos em Direito, vol. 1, nº. 2, jul. 2014, p. 184-198.

BUCCI, Maria Paula Dallari. Quadro de Referência de uma Política Pública: primeiras linhas de uma visão jurídico institucional. Diário do Estado, ${ }^{\circ}$. 122, 2016.

DE LUCCA, Daniel. A rua em movimento: experiências urbanas e jogos sociais em torno da população de rua. Dissertação (mestrado) - Faculdade de Filosofia Letras e Ciências Humanas da Universidade de São Paulo, São Paulo, 2007. 
DE LUCCA, Daniel. Nem dentro nem fora do albergue: transformações e usos de um dispositivo da assistência. In: $34^{\circ}$. Encontro Anual da Anpocs. Sobre periferias: novos conflitos no espaço público, 2010. Disponível em: $<$ http://www.academia.edu/2711369/Nem_dentro_nem_fora_do_albergue $>$.

DIEME, Kassoum. Imigração haitiana e política de acolhimento institucional na cidade de São Paulo: 2010-2015. Dissertação defendida no mestrado em Sociologia da Universidade Estadual de Campinas - UNICAMP 2016.

FERRO, Maria Carolina Tiraboschi. "Política Nacional para a População em Situação de Rua: o protagonismo dos invisibilizados." In: Revista Direitos Humanos, $n^{\circ}$. 8. Secretaria Nacional de Direitos Humanos da Presidência da República, jan. 2012.

FIPE, 2015. Censo da População em Situação de Rua. Disponível em $<$ http://www.prefeitura.sp.gov.br/cidade/secretarias/upload/assistencia_social/ observatorio_social/2015/censo/FIPEsmadsCENSO2015coletivafinal.pdf>.

FONSECA, Claudia; CARDARELLO, Andrea. Direitos dos mais e menos humanos. Horiz. antropol. Porto Alegre, v. 5, n. 10, p. 83-121, mai. 1999. Available from <http://www.scielo.br/scielo.php?script=sci_arttext\&pid=S0104$-71831999000100083 \& \operatorname{lng}=$ en\&nrm=iso $>$. Access on 15 feb. 2018. http:// dx.doi.org/10.1590/S0104-71831999000100005.

FRANGELLA, Simone Miziara. Corpos Urbanos Errantes: uma etnografia da corporalidade de moradores de rua em São Paulo. Dissertação apresentada na Universidade Estadual de Campinas, UNICAMP. Campinas: 2004.

GOMES, Janaína Dantas Germano. O Ouvir como uma Prática de Direitos Humanos: reflexões sobre as atividades da Clínica de Direitos Humanos Luiz Gama. Clínicas de Direitos Humanos e o Ensino Jurídico no Brasil: da Crítica à Prática que Renova. Belo Horizonte: Arraes Editores, 2017.

MOUTINHO, Laura. Diferenças e desigualdades negociadas: raça, sexualidade e gênero em produções acadêmicas recentes. Cad. Pagu, Campinas, n. 42, p. 201-248, jun. 2014. Available from <http://www.scielo.br/scielo.php?script=sci_arttext\&pid=S0104-83332014000100201\&ln $\mathrm{g}=$ en\&nrm=iso>. Access on 15 feb. 2018. http://dx.doi.org/10.1590/01048333201400420201 . 
PEIRANO, M. Etnografia não é método, 2014. Horizontes Antropológicos, Porto Alegre, ano 20, n. 42, p. 377-391, jul./dez. 2014.

RUI, Taniele. Relato de um impasse: introdução à trajetória de Nando. Revista de Antropologia do Social dos alunos do PPGAS-UFSCAR, v. 3, n. 1, jan./ jun., p. 353-373, 2010.

SANTANA, Carmen lúcia Albuquerque de; ROSA, Anderson. Saúde Mental das pessoas em situação de rua: conceitos e práticas para profissionais da assistência social. São Paulo: Epidaurus Medicina e Arte, 2016.

UEBEL, Roberto Rodolfo Georg et RUCKERT, Aldomar Arnaldo. Aspectos gerais da dinâmica imigratória no Brasil no século XXI. Confins Revista franco-brasilera de geografia [En ligne], 31 | 2017, mis en ligne le 8 juin 2017, consulté le 28 juillet 2017. URL: http://confins.revues.org/11905 ; DOI : 10.4000/confins. 11905

WIHTOL DE WENDEN, Catherine. Por que mais pessoas do que nunca estão em circulação e para onde elas estão indo? Dossiê sobre migração e direitos humanos. SUR - Revista Internacional de Direitos Humanos. 2016. Disponível em: <http://sur.conectas.org/as-novas-migracoes/>.

ZAMBONI, Marcio. Marcadores Sociais da Diferença. Sociologia: grandes temas do conhecimento (Especial Desigualdades), São Paulo, v. 1, p. 14 - 18, $1^{\circ}$. ago. 2014.

\section{LEGISLAÇÃO}

BRASIL. Decreto $\mathbf{n}^{\mathbf{0}}$. 7.053, de 23 de dezembro de 2009. Institui a Política Nacional para a População em Situação de Rua e seu Comitê Intersetorial de Acompanhamento e Monitoramento. Diário Oficial, Brasília, DF, 24 dez. 2009.

BRASIL. Lei $\mathbf{n}^{\mathbf{0}} \mathbf{. 8 . 7 4 2}$, de 7 de dezembro de 1993. Dispõe sobre a organização da assistência social e dá outras providências. Diário Oficial, Brasília, DF, 7 dez. 1993. 
SÃO PAULO. Lei no $\mathbf{0}$ 12.316, de 16 de abril de 1997. Dispõe sobre a obrigatoriedade do poder público municipal a prestar atendimento à população de rua na Cidade de São Paulo. Diário Oficial, São Paulo, SP, 16 abr. 1997.

SÃO PAULO. Decreto $\mathbf{n}^{\mathbf{0}} \mathbf{. 4 0 . 2 3 2}$ de $\mathbf{2}$ de janeiro de 2001. Regulamenta a Lei $\mathrm{n}^{\circ}$. 12.316, de 16 de abril de 1997, que dispõe sobre a obrigatoriedade do Poder Público Municipal a prestar atendimento à população de rua da Cidade de São Paulo, e dá outras providências. Diário Oficial, São Paulo, SP, 2 jan. 2001.

SÃO PAULO. Lei $\mathbf{n}^{\mathbf{0}} \mathbf{1 6 . 4 7 8}$ de 21 de junho de 2016. Institui a Política Municipal para a População Imigrante, dispõe sobre seus objetivos, princípios, diretrizes e ações prioritárias, bem como sobre o Conselho Municipal de Imigrantes. Diário Oficial, São Paulo, SP, 21 jun. 2016.

SÃO PAULO. Decreto $\mathbf{n}^{\mathbf{0}} \mathbf{.} \mathbf{5 7 . 5 3 3}$, de 15 de dezembro de 2016. Regulamenta Lei $n^{\circ} .16 .478 / 2016$, que institui a Política Municipal para População Imigrante. Diário Oficial, São Paulo, SP, 15 dez. 2016.

\section{SOBRE AS AUTORAS}

\section{Janaína Dantas Germano Gomes}

Doutoranda e Mestra em Direito pela Universidade de São Paulo. Professora de Direito da Pontifícia Universidade Católica de Campinas (PUCCAMP).

CV: http://lattes.cnpq.br/4188600282234626

janadgg@gmail.com

\section{Juliana Rocha Miranda}

Graduanda em Direito pela Universidade de São Paulo.

CV: http://lattes.cnpq.br/3451192802604287

juliana.rocha.miranda@usp.br

Submetido em:15-2-2018

Aceito em: 6-3-2018 